
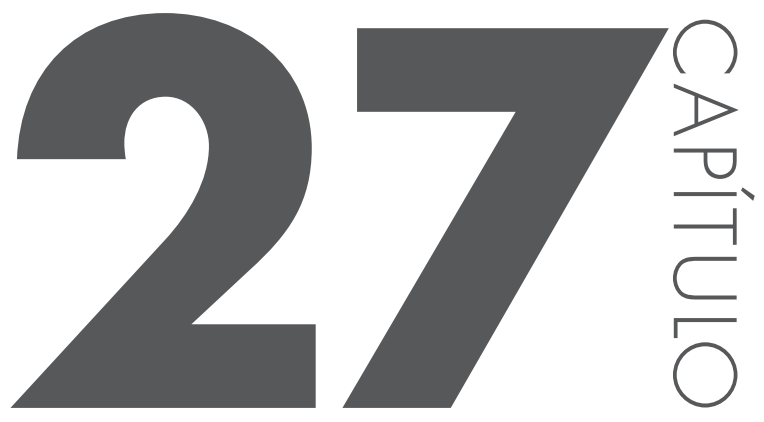

\title{
FUNDAMENTOS DA FISIOPATOLOCIA DA ÚlCera PÉPTICA E DO CÂNCER GÁstrICo
}

Lucia Libanez Bessa Campelo Braga

Gifone Aguiar Rocha

Andréia Maria Camargos Rocha

Dulciene Maria de Magalhães Queiroz 


\subsection{INTRODUC̣ÃO}

Até há aproximadamente três décadas, a patogenia da úlcera péptica (UP) era atribuída a um desequilíbrio entre a secreção ácida e os mecanismos de defesa da mucosa, cuja causa ou causas não eram conhecidas; entretanto, em 1982, na Austrália, Robin J Warren e Barry J Marshall isolaram uma bactéria, posteriormente denominada Helicobacter pylori, com origem em fragmentos de mucosa gástrica de pacientes com gastrite e úlcera duodenal. Estudos subsequentes em várias partes do mundo confirmaram a hipótese inicial de que a bactéria estaria associada à gênese da doença péptica ulcerosa em adultos e crianças.

Pouco mais de uma década depois do isolamento do H. pylori, em 1994, com base em estudos epidemiológicos e plausibilidade biológica a infecção foi classificada pelo Instituto para a Pesquisa do Câncer da Organização Mundial da Saúde como carcinógena.

Esses achados mudaram a compreensão sobre a fisiopatologia dessas duas doenças e; embora, tenha ocorrido um avanço significativo no conhecimento, muitos aspectos relativos à fisiopatologia da úlcera péptica e do câncer gástrico permanecem desconhecidos. Neste capítulo será abordada a fisiopatologia da úlcera péptica e do câncer gástrico, bem como o papel do H. pylori na gênese dessas doenças.

\section{2 ÚLCERA PÉPTICA}

\subsubsection{DEFINIÇÃO}

A UP é uma afecção heterogênea, multifatorial, que acomete $15 \%$ a $20 \%$ da população mundial. A úlcera é denominada péptica porque ocorre em sítios expostos à secreção de ácido clorídrico e pepsina. Ocorre mais frequentemente no estômago e duodeno, mas pode também acometer o terço inferior do esôfago, o jejuno, anastomoses gastroentéricas, e o divertículo de Meckel, quando existe mucosa gástrica ectópica. Em 90\% dos casos, a UP é uma lesão única; raramente dupla ou múltipla. Na maioria das vezes, apresenta-se como lesão arrendondada ou ovalada, com diâmetro variando de 0,5 a $2,0 \mathrm{~cm}$ e bordas regulares, pouco elevadas e cortadas a pique, tendendo a se afunilar na medida em que se aprofundam na parede do órgão. O fundo é geralmente limpo, mas pode estar coberto por material brancancento, por tecido de granulação avermelhado ou por tecido fibroso. A lesão pode estar restrita à submucosa, ou atingir a muscularis mucosae, serosa ou a cápsula ou parênquima de um órgão vizinho. De acordo com a profundidade da lesão e a intensidade da reação conjuntiva, a UP pode ser classificada em superficial, localizada na submucosa; profunda, quando atinge a lâmina 
própria; perfurante, quando ultrapassa todas as camadas da parede e se abre na cavidade peritoneal e penetrante, quando, além de ultrapassar todas as camadas fica tamponada por órgãos vizinhos (pâncreas, fígado, omento). A úlcera gástrica (UG) costuma apresentar dimensões maiores do que a duodenal (UD).

À microscopia, a úlcera em atividade apresenta quatro camadas bem reconhecidas, embora nem sempre bem individualizadas: 1) tecido necrótico, geralmente do tipo fibrinóide, presente no fundo da lesão decorrente da digestão ácido péptica; 2) exsudato inflamatório com predomínio de neutrófilos; 3) camada constituída principalmente por tecido de granulação; e 4) tecido fibroso cicatricial. Nas úlceras inativas, a camada superficial de necrose é escassa ou inexistente e, consequentemente, o exsudato de neutrófilos é discreto.

A UP se localiza mais frequentemente no duodeno, $95 \%$ na primeira porção do órgão, a três centímetros da junção do piloro com a mucosa duodenal. No estômago, $60 \%$ das UP localizam-se no antro, e em $25 \%$ dos casos na pequena curvatura, na junção do antro com o corpo. A UD acomete indivíduos mais jovens, dos 20 aos 40 anos de idade e a UG é mais frequente em pessoass acima de 40 anos de idade, com pico de incidência em torno dos 60 anos.

\subsubsection{ETIOLOGIA}

Embora a doença ulcerosa péptica seja multifatorial, diversos fatores etiológicos estão bem estabelecidos como a infecção pelo $H$. pylori e o uso crônico de anti-inflamatórios não esteroides (AINES).

A infecção por $H$. pylori pode ser responsabilizada por $90-95 \%$ das UD e $70-75 \%$ das UG. A erradicação do microrganismo reduz dramaticamente a taxa de recorrência da doença para 5\% ao ano, em contraposição a taxas de 70-85\% observadas quando os tratamentos convencionais, que não visam erradicação do H. pylori, são adotados.

O uso de AINEs é, provavelmente, a causa mais comum de lesões na mucosa gastrointestinal nos países desenvolvidos, onde a prevalência da infecção pelo H. pylori vem diminuindo rapidamente. O uso de AINEs é responsabilizado por aproximadamente $25 \%$ das UG, sendo considerado causa mais frequente de úlceras não decorrentes da infecção pelo H. pylori. UP assintomática pode ser encontrada endoscopicamente em aproximadamente $15-45 \%$ das pessoas que fazem uso crônico de AINES.

Outras causas menos comuns de úlcera incluem gastrinoma, mastocitose, pâncreas anular, doença de Crohn, infecção gástrica por outras espécies de $\mathrm{He}$ licobacter como o Helicobacter suis e possivelmente por outros microrganismos como Herpes simplex tipo I. As lesões ulcerosas pépticas têm também sido descrita em indivíduos que fazem uso de medicamentos contendo potássio, em pacientes submetidos à quimioterapia, usuários de cocaína, e mais recentemente 
sob tratamento para osteoporose com bifosfonatos de cálcio como alendronato e risedronato.

Ocasionalmente, algumas úlceras são definidas como idiopáticas, mas, na prática, a maioria delas é causada pelo uso não relatado de AINEs ou decorre da infecção pelo $H$. pylori que, entretanto, não foi diagnosticada em decorrência de resultados falso-negativos nos testes usados para o diagnóstico.

\subsection{BASES FISIOPATOLÓGICAS}

\subsubsection{FISIOLOGIA DA SECREÇÃO GÁSTRICA}

A célula parietal é responsável pela secreção gástrica de ácido clorídrico em decorrência da ativação da $\mathrm{H}^{+} \mathrm{K}^{+}$ATPase, denominada bomba de prótons, que se localiza na membrana luminal da célula. O suco gástrico facilita a digestão de proteínas e absorção de ferro, cálcio e vitamina B-12, além de prevenir a colonização da mucosa gástrica pela maioria das bactérias e fungos.

A secreção gástrica de ácido é regulada por três vias, tendo como agonistas a acetilcolina (via neuronal); a histamina (via parácrina) e a gastrina (via endócrina). Esses mediadores interagem com receptores acoplados a duas importantes vias sinalizadoras: adenilato ciclase, no caso da histamina e cálcio intracelular no caso da gastrina e acetilcolina.

A acetilcolina liberada por neurônios pós-ganglionares do nervo vago estimula diretamente a secreção do ácido, atuando em receptores muscarínicos M3 localizados na membrana basolateral da célula parietal e, indiretamente, por inibição da secreção de somatostatina cuja função é inibir a liberação de histamina pelas células enterocromafin-like (ECL) e de gastrina pelas células G localizadas na região do antro gástrico.

A histamina, gerada pela descarboxilação da L-histidina sob ação catalítica da enzima histidina-descarboxilase (HDC), estimula a secreção gástrica de ácido depois de se ligar aos receptores de histamina-2 (H2) localizados nas células parietais, desencadeando uma cascata de eventos, que resulta no aumento dos níveis intracelulares de adenosina monofosfato cíclico (AMPc). A histamina estimula, ainda, a secreção gástrica de ácido de maneira indireta, ao inibir a secreção de somatostatina pelas células D localizadas no antro gástrico e por estimular a liberação de gastrina pelas células $\mathrm{G}$.

A gastrina é o principal estimulador da secreção ácida durante a ingestão de alimentos, e age principalmente liberando histamina das células ECL localizadas no corpo e fundo do estômago. A gastrina liga-se a receptores de gastrina/colecistocinina do tipo 2 (CCK-2), localizados nas células ECL e também nas células 
parietais. A ativação dos receptores CCK-2 localizados nas células ECL parece ser a principal via pela qual a gastrina estimula a secreção ácida.

A somatostatina inibe a secreção gástrica impedindo a secreção de histamina e gastrina. É sintetizada a partir de uma molécula precursora denominada preprossomatostatina, liberada pelas células D localizadas na mucosa do corpo e antrogástricos. A redução significativa do $\mathrm{pH}$ no lúmen gástrico induz a um aumento de produção de somatostatina que, por sua vez, inibe a liberação de histamina e gastrina.

\subsubsection{MECANISMOS DE DEFESA DA MUCOSA GASTRODUODENAL}

O epitélio gástrico é constantemente agredido por fatores nocivos endógenos, como o $\mathrm{HCl}$, a pepsina, os sais biliares, a variação ampla de $\mathrm{pH}$, a pressão osmótica e temperatura ou substâncias exógenas, como medicamentos, álcool e microrganismos.

Os mecanismos de defesa incluem a barreira muco-bicarbonato-fosfolipídes, a rápida renovação celular, o fluxo sanguíneo da mucosa e a produção de prostaglandinas e óxido nítrico.

A barreira muco-bicarbonato-fosfolipídeos, a primeira linha de defesa da mucosa gástrica, é formada pelo muco, bicarbonato e fosfolipídios surfactantes que recobrem a superfície da mucosa. A barreira retém o bicarbonato secretado pelas células da superfície epitelial para que o microambiente permaneça neutro. A secreção de muco é estimulada por hormônios gastrointestinais, como gastrina e secretina, bem como por prostaglandina E2 (PGE2) e agentes colinérgicos. Quando há perda da integridade da barreira, outros mecanismos protetores são acionados, como a neutralização do ácido intracelular, aumento na rapidez de reparação epitelial, bem como manutenção e distribuição do fluxo sanguíneo da mucosa.

O epitélio da mucosa é renovado continuamente por um processo bem coordenado e uma proliferação controlada das células progenitoras, localizadas no colo das glândulas oxínticas.

A mucosa do estômago assim como a do duodeno é amplamente vascularizada o que contribui para o aporte de oxigênio, nutrientes e a remoção de substâncias tóxicas.

A produção contínua de prostaglandinas - principalmente a PGE2 e PGI2 - é também responsável pela manutenção da integridade da mucosa e proteção contra agentes que causam lesão epitelial. Prostaglandinas inibem ainda a ativação de mastócitos e leucócitos, bem como a aderência de plaquetas ao endotélio vascular.

O óxido nítrico, no trato gastrointestinal, atua na manutenção da homeostase, pelo seu papel citoprotetor e regulador do fluxo sanguíneo. 


\subsubsection{PATOGENIA DA ÚLCERA PÉPTICA}

De maneira geral, a UP decorre de um desequilíbrio entre os mecanismos de defesa e os fatores de agressão da mucosa gastroduodenal.

Historicamente, a compreensão da fisiopatologia da UP estava centrada principalmente na hipersecreção gástrica de ácido e pepsina. Entretanto, atualmente, sabe-se que a doença é multifatorial, decorrendo de desequilíbrios na fisiologia da secreção dos hormônios gástricos, gastrina e somatostatina induzidos pela infecção pelo H. pylori.

As úlceras gástricas que se localizam no corpo gástrico e simultaneamente no duodeno (UG tipo II) bem como aquelas localizadas na região pré-pilórica apresentam alterações da secreção ácida semelhantes àquelas observadas nos pacientes com úlcera duodenal, frequentemente, acompanhadas de níveis elevados de pepsinogênio I. Por outro lado, as úlceras que se localizam no corpo ou fundo do estômago (UG tipo I) estão associadas à menor secreção ácida, acompanhada ou não de diminuição da densidade de células parietais, alterações que têm sido atribuídas à pangastrite decorrente da infecção por $H$. pylori.

Antes da descoberta do H. pylori, a UD era considerada um distúrbio primário na homeostase da secreção ácida. Sob a luz dos conhecimentos atuais, foi possível demonstrar que algumas alterações observadas nos pacientes com UD, como concentração sérica elevada de pepsinogênio I e de gastrina, são consequências reversíveis da infecção pelo $H$. pylori. A secreção de bicarbonato bastante diminuída nos pacientes com UD parece também estar associada com a infecção pela bactéria.

$\mathrm{Na}$ infecção, especialmente por amostras mais virulentas, há aumento da expressão de citocinas pró-inflamatórias, interleucina-1 beta (IL-1b), IL-8, e fator de necrose tumoral alfa (TNF-a), que afetam a secreção de muco, a concentração de $\mathrm{HCO} 3$, bem como a secreção ácida, por atuarem nas células D inibindo a produção de somatostatina com consequente hipergastrinemia e aumento da secreção ácida. Entre outras consequências da infecção, vale mencionar que a bactéria induz a liberação de vários compostos como COX-2, o que pode comprometer a integridade da mucosa pela formação de outras substâncias pró-inflamatórias, como produtos reativos do oxigênio (ROS).

A redução da secreção duodenal de $\mathrm{HCO}^{-}$e de muco resultante da infecção torna a mucosa duodenal permeável e susceptível à ação de íons $\mathrm{H}^{+}$, favorecendo sua substituição por mucosa gástrica metaplásica. A bactéria da mucosa do estômago migra e coloniza as áreas de metaplasia gástrica no duodeno, onde estimula a resposta inflamatória local, predispondo à formação do nicho ulceroso.

A infecção por cepas de $H$. pylori mais virulentas está associada com um risco aumentado de desenvolver UP. Dentre os fatores de virulência que não são 
expressos por todas as linhagens de H. pylori, devem ser mencionados a citotoxina vacuolizante (VacA), a ilha de patogenicidade (PAI) cag, os genes babA (blood group antigen-binding adhesin), sabA (sialic acid-binding adhesin A), oipA (outer inflammatory protein A), e ice A (induced by contact with epithelium) com destaque para os dois primeiros que serão descritos a seguir.

O gene vacA (vacuolating cytotoxin), presente em todas as amostras de $H$. pylori, codifica a proteína VacA, uma exotoxina que induz na célula epitelial a formação de vacúolos intracitoplasmáticos e a destruição de mitocôndrias com liberação de citocromo c e morte celular por apoptose. VacA estimula ainda a resposta inflamatória da mucosa gástrica por diferentes mecanismos, como por exemplo, pelo aumento da expressão de COX-2, não somente em células T, mas também em neutrófilos e macrófagos. Nas regiões sinalizadora e média do gene vacA há dois polimorfismos, denominados $\mathrm{s} 1$ e s 2 e $\mathrm{m} 1$ e $\mathrm{m} 2$, respectivamente; recentemente foram descritas outras regiões polimórficas, uma localizada na região intermediária (i) do gene com dois genótipos distintos; i1 e i2 e outra localizada no sítio de clivagem da proteína com dois genótipos d1 e d2. As amostras s1m1 são consideradas as mais toxigênicas, as $\mathrm{s} 1 \mathrm{~m} 2$ produzem quantidades moderadas de toxina e as amostra s $2 \mathrm{~m} 2$ produzem pouca ou nenhuma toxina. vacA s1, i1, d1 e m1 estão associadas com um risco aumentado de UP.

A ilha de patogenicidade cag (PAI) contém vários genes de virulência, tais como o cagA. A infecção por linhagens cagPAI-positivas está associada com maior grau de inflamação gástrica, o que é atribuído ao aumento de secreção de IL-8 pelas células epiteliais e ao risco aumentado de UP.

A associação entre a infecção por amostras de $H$. pylori vacA s1m1 e cagA-positivas e risco aumentado de UP foi observada pelo nosso grupo e por pesquisadores de outros pacientes ocidentais.

Como mencionado anteriormente, os AINEs são a segunda causa mais frequente de UP, especialmente, as UG.

Acredita-se que os AINEs promovam lesão na mucosa gástrica e duodenal por dois mecanismos: efeito tóxico direto alterando os mecanismos de defesa da mucosa com aumento da permeabilidade celular, inibição do transporte iônico e da fosforilação oxidativa, e por efeito sistêmico, enfraquecendo os mecanismos de defesa pela inibição da COX-1, que atua na síntese das prostaglandinas.

Os efeitos deletérios da COX-1 decorrem principalmente da inibição da síntese de PGs, visto que são mediadores importantes de mecanismos de defesa. As PGs além de estimularem a secreção de muco e bicarbonato o que torna a mucosa mais resistente à penetração do ácido, participam na reparação da mucosa, aumentam o fluxo sanguíneo e promovem a replicação celular. A identificação de um segundo tipos de ciclooxigenase (COX-2) contribuiu para o desenvolvimento de um novo grupo de drogas antiinflamatórias, os inibidores específicos da COX- 
2. Esses agentes são eficazes em aliviar a dor e a inflamação, não afetam significativamente a produção de PG e causam alterações discretas na mucosa gástrica, já que não interferem com a produção de COX-1.
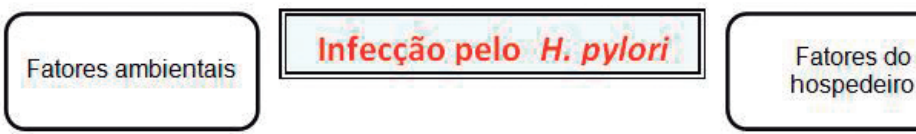

Fatores do hospedeiro
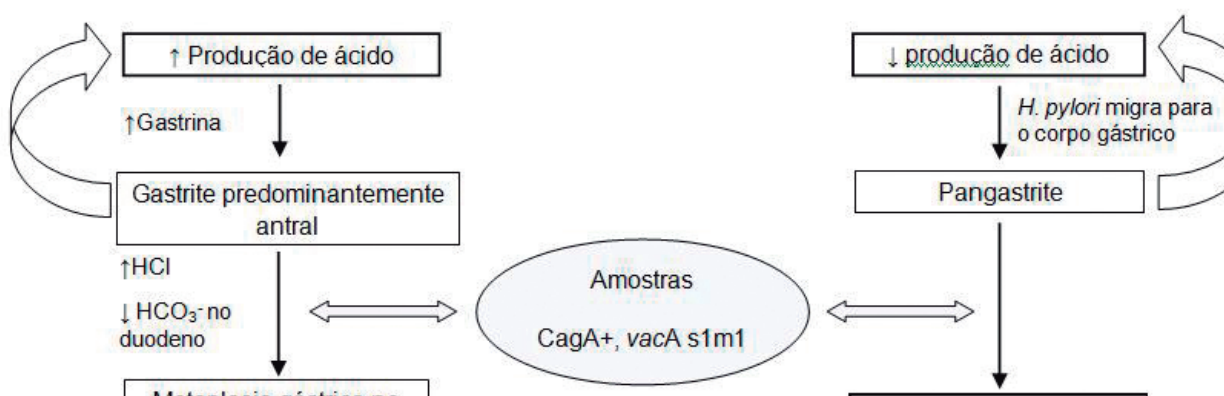

Metaplasia gástrica no duodeno com colonizacão pelo H. pvlori

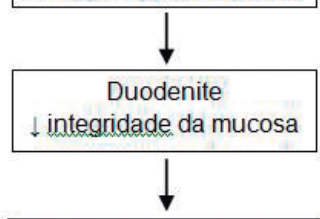

Úlcera duodenal

Figura 27.1 - Interações do hospedeiro com o meio ambiente e infecção por H. pylori no desenvolvimento de úlceras gástricas e duodenais: 0 curso clínico da infecção pelo H. pylori é altamente variável e depende do padrão de distribuiç̣̃o da gastrite, da virulência da linhagem de $H$. pylori, da susceptibilidade genética do hospedeiro, da idade de aquisição da infecção e de fatores ambientais. Esses fatores favorecem a colonização do corpo do estômago pelo $\mathrm{H}$. pylori que resulta em pangastrite e, consequentemente, redução na secreção de ácido. A hipocloridria decorrente da colonização pelo H. pylori e da inflamação intensa no corpo pode resultar no desenvolvimento de atrofia gástrica, úlera gástrica e câncer. Pacientes com gastrite predominantemente antral apresentam secreção gástrica de ácido normal ou elevada e hipergastrinemia e estão predispostos a desenvolver úlcera duodenal. Ocorre, ainda, diminuição da secreção de HC03- e muco. A mucosa duodenal se torna permeável e é agredida pelos íons $\mathrm{H}^{+} \mathrm{e}$ outros irritantes, sendo substituída por mucosa gástrica metaplásica. A bactéria presente na mucosa do estômago migra e coloniza as áreas de metaplasia gástrica no duodeno, onde estimula a resposta inflamatória local predispondo à formaç̃õo do nicho ulceroso. Figura adaptada de CHAN \& LEUNG. The Lancet,V.360, p.935, 2002.

\subsection{CÂNCER GÁSTRICO}

O carcinoma gástrico é o quarto tumor mais frequente e, a terceira causa de morte por câncer no mundo, sendo responsável por aproximadamente $12 \%$ da 
mortalidade mundial por câncer. Acomete aproximadamente de um milhão de pessoas por ano, preferencialmente do sexo masculino, na proporção de dois para um. A incidência da doença varia de acordo com a região geográfica, sendo mais elevada em países do nordeste da Ásia como Japão, Coréia e China, onde ocorrem 69 casos por 100.000 habitantes por ano. Incidência intermediária é relatada na Europa, América do Sul e América do Norte. Na África, sul da Ásia e oceânia, incluindo Nova Zelândia e Austrália, as taxas estão em torno de quatro casos por 100.000 habitantes por ano.

No Brasil ocorreram cerca de 22.000 mortes em razão da doença no ano de 2014 (INCA, 2014). Dados do INCA (2014) indicam, ainda, que o tumor é o quarto mais frequente entre os homens e o quinto entre as mulheres no Brasil, com ocorrência estimada de 21.390 casos novos em 2014.

\subsubsection{CLASSIFICAÇÃO}

As neoplasias gástricas são predominantemente malignas e dentre elas 90 a $95 \%$ são adenocarcinomas. Outras neoplasias observadas menos frequentemente incluem os linfomas, especialmente do tipo MALT (tecido linfóide associado à mucosa), que representam $2 \%$ a $8 \%$ dos tumores gástricos e mais raramente os sarcomas e leimiossarcomas.

Os adenocarcinomas gástricos são classificados em dois tipos, de acordo com a localização anatômica, quais sejam os tumores proximais (localizados na cardia) e distais (não localizados na cardia). Os tumores são também classificados de acordo com parâmetros morfológicos e histológicos nos tipos descritos por Laurén: tipo intestinal (bem diferenciado - aproximadamente 50\% dos casos), tipo difuso (indiferenciado - ao redor de 33\%) e tipo misto ou não classificável.

Os carcinomas distais estão associados com a infecção pelo $H$. pylori, enquanto os proximais guardam relação com doença do refluxo gastrosofagiano e não se associam com a infecção pelo microrganismo.

\subsection{1. ADENOCARCINOMA GÁSTRICO DO TIPO INTESTINAL}

O adenocarcinoma do tipo intestinal é mais prevalente nos países em desenvolvimento, em populações de baixo nível socioeconômico que vivem em moradias com índices de aglomeração elevados e condições de higiene precárias. Ao contrário, a prevalência do tumor tem diminuído significativamente nos países desenvolvidos, onde, entretanto, as taxas de incidência e prevalência de câncer proximal e de esôfago são cada vez mais elevadas. Esses achados parecem ter relação direta com a prevalência da infecção pelo $H$. pylori.

A infecção pelo microrganismo é adquirida precocemente na infância, há um longo período de latência, e o câncer ocorre em $1 \%$ dos indivíduos infectados, 
geralmente depois da quarta década de vida. Nesse período, ocorre no estômago uma cascata de eventos com estágios histopatológicos bem característicos: gastrite crônica em atividade, ou seja, com presença de polimorfonucleares, gastrite atrófica multifocal, metaplasia intestinal (completa e incompleta), displasia e carcinoma. $\mathrm{O}$ tumor localiza-se preferencialmente no antro e na incisura angularis.

Como já relatado, o adenocarcinoma gástrico distal é classificado de acordo com Laurén em dois tipos; difuso e intestinal. O tipo difuso é menos frequente, mais agressivo e acomete pessoas mais jovens e o tipo intestinal acomete mais comumente indívíduos idosos. $\mathrm{O}$ adenocarcinoma do tipo intestinal se desenvolve a partir de uma série de lesões sequenciais que ocorrem na mucosa gástrica de acordo com o modelo proposto por Pelayo-Correa. O processo inicia-se quando o H. pylori coloniza preferencialmente a mucosa do antro gástrico, respeitando o corpo e fundo gástricos, regiões onde o pH é mais ácido. A resposta imunológica induzida pela bactéria pode variar em intensidade, mas usualmente causa uma gastrite crônica não atrófica que persiste por décadas. A infecção pode progredir para a região proximal do estômago levando progressivamente à perda do tecido glandular (gastrite atrófica multifocal). A atrofia, na maior parte das vezes, inicia-se na incisura angularis e pode estender-se para a mucosa do antro ou do corpo. Em alguns pacientes com gastrite atrófica multifocal, as glândulas gástricas são substituídas por estruturas glandulares com fenótipo intestinal, características de glândulas do intestino delgado (metaplasia intestinal - MI - completa) ou epitélio do colon (MI incompleta). Na MI do tipo completo o epitélio gástrico assemelha-se ao epitélio do intestino delgado, ou seja, exibe enterócitos eosinofílicos com bordas em escova bem definidas, representando microvilosidades absortivas, células caliciformes bem formadas que secretam sialomucinas e mesmo a presença de células de Paneth. A MI incompleta lembra o fenótipo do epitélio do intestino grosso onde são observadas células caliciformes contendo no seu citoplasma gotas de mucina de tamanhos variados, ausência de borda em escova que, entretanto, pode ser observada eventualmente, e ausência de células de Paneth. Há evidências de que a MI do tipo incompleto está associada com risco aumentado de câncer gástrico. Em uma pequena porcentagem de pacientes com MI, a lesão eventualmente progride para displasia (neoplasia intraepitelial, neoplasia não invasora) que é classificada como de baixo, médio ou alto grau. Displasia é uma lesão plana, caracterizada pela presença de atipias celulares e distúrbios da proliferação e diferenciação celulares que se originam, na maioria dos casos, em focos de MI, quase sempre do tipo incompleto. As atipias celulares caracterizam-se pelo pleomorfismo, hipercromasia e estratificação nuclear, aumento da relação núcleo citoplasma, aumento da basofilia do citoplasma e perda da polaridade celular. Diferenciação anormal manifesta-se pela redução, desaparecimento ou alteração da secreção de muco e por perda ou redução do número de células caliciformes 
e de células absortivas (quando estão na MI). O aumento da proliferação celular e a desorganização da arquitetura celular expressam-se pelos núcleos contendo macronucléolos, figuras de mitose, irregularidades, projeções ou ramificações das criptas, crescimento papilar intraluminal e superficial do epitélio, despolarização e justaposição glandulares.

A erradicação do $H$. pylori com antimicrobianos antes do aparecimento da atrofia gástrica parece prevenir o surgimento do câncer gástrico.

Os mecanismos responsáveis pela progressão da atrofia para o câncer gástrico não são completamente conhecidos; entretanto, há hipóteses que incluem o papel da hipocloridria favorecendo o supercrescimento de outras bactérias que não o H. pylori que liberam substâncias reativas do oxigênio e nitrogêno (RNOS e RNS) que induzem mutações no DNA. Os radicais livres produzidos pelas células inflamatórias, especialmente polimorfonucleares neutrófilos, podem ser agentes carcinogênicos. A hipergastrinemia compensatória que acompanha a hipocloridria pode também contribuir para a carcinogênese uma vez que a gastrina promove hiperproliferação celular. Camundongos transgênicos com hipergastrinemia desenvolvem, em curto prazo, câncer gástrico quando tratados com carcinógenos.

\subsection{2. ADENOCARCINOMA DIFUSO}

O adenocarcinoma do tipo difuso é mais comum em pessoas mais jovens de populações com menor risco de câncer, mas há evidências de que também decorre da infecção pelo H. pylori. À microscopia, as células tumorais, denominadas de células em anel de sinete, são geralmente arredondadas e pequenas, isoladas com coesão intercelular mínima ou ausente. Mutação somática no gene CDH1 que codifica a E-caderina é encontrada em mais $50 \%$ dos tumores gástricos do tipo difuso em populações caucasiana e japonesa e está associada com pior prognóstico.

A E-caderina é uma proteína ubíqua que se localiza nas junções das células epiteliais, e atua efetivamente como uma ponte entre as proteínas do citoesqueleto de células adjacentes, função fundamental para a manutenção da arquitetura do epitélio tissular. A inibição da expressão de E-caderina é caracterizada pela fragilidade da interação célula-célula, impedindo a formação de glândulas. A mutação somática do gene CHD1 é considerada um evento tardio na gênese dos tumores, sugerindo que a proteína inibe a invasão das células tumorais e metástases.

A mutação do gene $C D H 1$ pode ocorrer também em células germinativas e, nesse caso, associa-se com o adenocarcinoma gástrico difuso hereditário que resulta de uma alteração autossômica dominante, contribuindo com menos de $1 \%$ dos tumores gástricos. Há pelo menos 27 mutações, bem documentadas, no gene CDH1, que se localizam em distintos exons e geram uma proteína truncada. O alelo mutante do CDH1 apresenta um grau elevado de penetrância; indivíduos do 
sexo masculino carreadores do genótipo mutado têm um risco de $67 \%$ de desenvolver o câncer difuso hereditário ao longo da vida, enquanto no sexo feminino o risco é de $83 \%$.

Além das mutações citadas, inativação epigenética da E-caderina por hipermetilação e perda da heterozigose tem sido frequentemente relatada no câncer gástrico difuso. Indivíduos que carreiam o alelo que sofreu mutação e são infectados pelo $H$. pylori têm risco significativamente mais aumentado de desenvolver a doença.

\subsection{3. ADENOCARCINOMA GÁSTRICO PROXIMAL}

Embora a prevalência de câncer gástrico distal esteja diminuindo nos países desenvolvidos, há um aumento significativo na incidência e prevalência dos adenocarcinomas gástricos proximais, incluindo os tumores da junção esôfago-gástrica.

A compreensão da etiologia e origem do câncer localizado na junção esôfago-gástrica é um dasafio para cirurgiões, gastroenterologistas e patologistas, uma vez que não há consenso entre as especialidades e a determinação da origem do tumor é decisiva para orientar a conduta cirúrgica que difere de acordo com a localização.

Os adenocarcinomas localizados no esôfago distal, a menos de cinco centímetros da junção esôfago-gástrica apresentam características histológicas e epidemiológicas semelhantes às dos adenocarcinomas de esôfago, ou seja, predominam no sexo masculino, estão associados com refluxo gastroesofagiano e à histologia são do tipo intestinal de Laurén. Por outro lado, os tumores localizados nos cinco primeiros centímetros à jusante da junção esôfago-gástrica assemelham-se aos tumores de estômago distal, havendo um predomínio discreto no sexo masculino, proporção semelhante de tumores do tipo intestinal e difuso e ausência de associação com doença do refluxo gastroesofagiano. Os tumores localizados na junção esôfago-gástrica têm características intermediárias entre os dois tipos descritos acima; alguns decorrem do refluxo gastroesofagiano e outros são originários do estômago mas apresentam características macroscópicas e histológicas semelhantes que não permitem distingui-los. Há, portanto, necessidade de se investigarem outros parâmetros obtidos pela história clínica e avaliação histológica do antro e corpo gástricos. Os tumores localizados na junção esôfago-gástrica de pacientes com história de doença do refluxo gastroesofagiano e ausênica de gastrite atrófica do corpo são geralmente de origem esofágica; já aqueles que surgem em pacientes com gastrite atrófica do corpo são geralmente de procedência gástrica.

Alcoolismo e tabaco são considerados fatores de risco importantes para o câncer da cárdia nos países desenvolvidos. Por outro lado, em determinadas regiões da China, onde o tumor tem uma prevalência de aproximadamente 
$20 \%$, esses fatores são considerados de baixo risco, sendo a história familiar e deficiência alimentar os fatores de risco mais relevantes. Nessa população, recentemente, foi descrita uma mutação no gene PLCE1 que codifica a fosfolipase C1e que pertence à família da fosfolipase $\mathrm{C} 1$ associada com risco aumentado de adenocarcinoma da cárdia sem; entretanto, associar-se com o tumor gástrico distal. Denomina-se fosfolipase C1 um grupo constituído por pelo menos seis isoenzimas que atuam na defosforilação de fosfofoinositídeos, fosfolipídeos componentes da membrana celular, responáveis pela regulação de grande parte das funções celulares, como sobrevida, proliferação, crescimento, motilidade, polimerização de filamentos de actina e adesão célula-célula PLCe1, além de interagir com o proto-oncogene RAS, estimula a expressão de citocinas pró-inflamatórias e quimiocinas como IL-1 $\alpha$ e CXCL2 induzindo inflamação crônica, substrato de muitos tipos de câncer.

\subsection{4. LINFOMA MALT}

O linfoma MALT (tecido linfóide associado à mucosa) é a segunda neoplasia maligna mais comum oo estômago, sendo responsável por $2 \%$ a $8 \%$ dos tumores malignos do órgão. Mais de $95 \%$ dos linfomas gástricos primários são linfomas não Hodgkin e entre eles, mais de $90 \%$ são de células B. Aproximadamente 50\% dos linfomas gástricos de células B são de baixo grau, de crescimento indolente, permanecendo localizados por longos períodos de tempo. Os demais linfomas gástricos são de alto grau e parecem ser resultantes da progressão de um linfoma de baixo grau.

A relação causal entre $H$. pylori e o linfoma gástrico MALT foi estabelecida com base em estudos epidemiológicos de coortes, pela identificação da bactéria em fragmentos de biopsia gástrica dos pacientes com o tumor e no fato de que a erradicação da bactéria com antimicrobianos pode levar à cura da neoplasia. $\mathrm{O}$ tumor formado por linfócitos B monoclonais, inicialmente é dependente de linfócitos $\mathrm{T}$ helper estimulados por antígenos bacterianos. Nessa fase, a erradicação da bactéria é acompanhada frequentemente de cura da lesão. Em estágios mais avançados, o crescimento dos linfócitos B independe dos linfócitos T e consequentemente do estímulo bacteriano.

\subsubsection{FATORES DE RISCO PARA O CÂNCER GÁSTRICO}

Embora os mecanismos envolvidos na gênese do câncer gástrico não sejam completamente conhecidos, a interação dos fatores genéticos do hospedeiro com fatores ambientais e fatores de virulência do $H$. pylori é considerada crucial no surgimento do tumor. 
O Quadro 27.1 mostra os principais fatores de risco associados ao câncer gástrico.

Quadro 27.1 - Fatores associados com adenocarcinoma gástrico

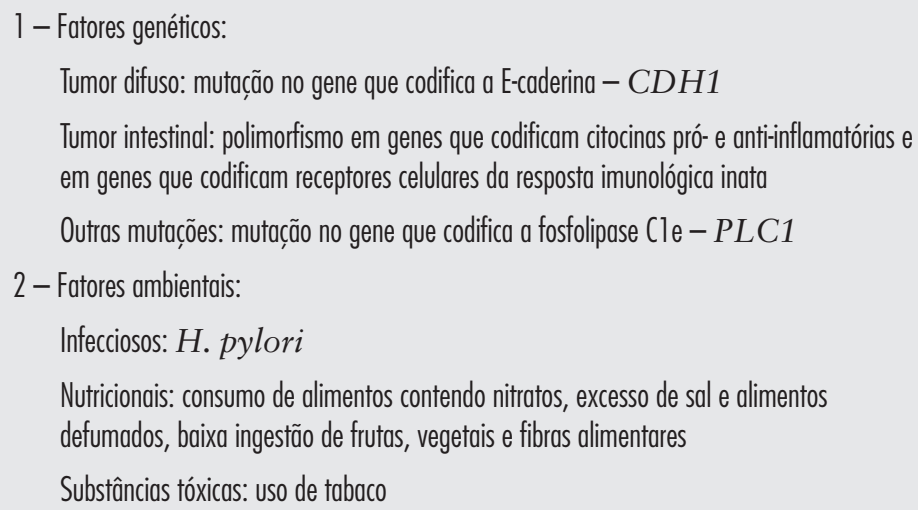

\subsubsection{FATORES DO HOSPEDEIRO}

A associação entre inflamação crônica e câncer é bem estabelecida, inclusive no caso do adenocarcinoma gástrico. O processo inflamatório de longa duração pode causar lesões irreversíveis que culminam com o aparecimento do tumor. Fatores genéticos do hospedeiro podem influenciar a natureza e a intensidade da resposta inflamatória ao $H$. pylori. Os genótipos polimórficos do gene IL1B nas posições -31C e -511T, que codificam as citocinas pró-inflamatórias, interleucina-1 alfa (IL-1 $\alpha$ ) e IL-1 $\beta$, o alelo longo do IL1RN que codifica o antagonista do receptor da IL-1 (IL1ra), e o alelo polimórfico localizado na posição -308 do TNFA que codifica o fator de necrose tumoral (TNF- $\alpha$ ) foram vistos estar associados com um risco aumentado de hipocloridria, lesões gástricas acentuadas e carcinoma gástrico distal em populações caucasianas. A citocina pró-inflamatória IL-1 $\beta$, cuja expressão está aumentada na infecção pelo $H$. pylori, desempenha um papel fundamental na iniciação e ampliação da resposta inflamatória à infecção pela bactéria, sendo também um inibidor potente da secreção ácida. Tem sido sugerido que a inibição da secreção ácida favorece a migração do $H$. pylori do antro para o corpo gástrico causando uma pangastrite de intensidade acentuada que favorece o desenvolvimento de atrofia, lesão que precede o aparecimento do câncer gástrico. Estudos de meta-análise demonstraram que os polimorfismos nos genes $I L 1 B-31 \mathrm{C}$ e $I L 1 R N^{*} 2$ estão associados com risco aumentado de câncer gástrico na população ocidental, mas não na população asiática. Diferentemente, resultados obtidos na população brasileira pelo nosso grupo demonstram que somente o alelo longo do ILRN*2 está associado com carcinoma gástrico. Também observamos que a expressão de IL-1b está significativamente aumentada na 
mucosa gástrica de carreadores do alelo 2 polimórfico do IL1RN, mas não do alelo polimórfico do gene IL1B.

Polimorfismos em genes que codificam outras moléculas associadas à resposta imunológica como IL-10 e receptores toll-like-4 (TLR-4) têm sido também associados com risco aumentado de câncer gástrico.

\subsubsection{FATORES DE VIRULÊNCIA DO H. PYLORI}

À semelhança do que ocorre na UP, a infecção por linhagens de H. pylori mais virulentas está associada com um risco aumentado de câncer gástrico. Assim, pacientes com carcinoma gástrico distal são mais frequentemente colonizados por amostras da bactéria carreadores da ilha de patogenicidade cagPAI e genótipo s1i1d1m1 do vacA.

A ilha de patogenicidade cagPAI é o fator de virulência do $H$. pylori mais estudado e compreende um fragmento de DNA de $40 \mathrm{~kb}$ contendo cerca de 31 genes. O conteúdo de GC $(35 \%)$ da cag PAI difere do conteúdo GC do restante do genoma da bactéria (39\%), sugerindo aquisição horizontal. Alguns genes da ilha codificam proteínas do sistema de secreção do tipo IV (SST4) responsável pela translocação da proteína CagA, de 120 a $145 \mathrm{kDa}$, para o citosol das células epiteliais gástricas.

A proteína CagA foi recentemente reconhecida como a primeira proteína de origem bacteriana com propriedades oncogênicas. A região carboxi-terminal da proteína CagA contém sítios de fosforilação denominados EPIYA por serem sequências constituídas de cinco aminoácidos (Glu-Pro-Ile-Tyr-Ala). As amostras têm dois EPIYAs denominados A e B e um terceiro com variações regionais na sequência de aminoácidos denominado EPIYA-C, nas amostras isoladas nos países ocidentais ou EPIYA-D nas amostras isoladas de países asiáticos. Essas denominações se devem a diferenças de aminoácidos que flanqueiam as sequências EPIYA. Quinases da família Src, originárias das células do hospedeiro, fosforilam as sequências EPIYA no aminoácido tirosina. Uma vez fosforilada, a proteína CagA é recrutada e localiza-se na membrana celular onde interage com dois domínios SH2 presentes em proteínas da família tirosina fosfatase, dentre elas SHP-2. É conhecida a associação entre tumores em seres humanos e perda ou ganho de função de fosfatase SHP-2. A interação de CagA com os dois domínios SH2 induz mudanças na conformação da fosfatase SHP-2, aumenta a atividade da enzima e ativa a via SHP-2/MAPK/ERK1/2, desencadeando alterações no citoesqueleto celular responsáveis pela formação de pedestais, que permitem maior aderência bacteriana, e por alongamento das células epiteliais que adquirem o fenótipo denominado "hummingbird" (beija-flor). Essas mudanças no citoesqueleto desregulam o crescimento celular, o contato célula/célula e a migração celular, aumentando, assim, o risco de lesão celular e consequentemente de aquisição de mutações genéticas que predispõem ao câncer. 
O principal sítio de fosforilação encontra-se nas EPIYA-C e D. O sítio D fosforilado confere maior afinidade de ligação à SHP-2 que o sítio C. Entretanto, quando ocorrem duas a três repetições da sequência EPIYA-C há também maior afinidade de ligação CagA/SHP-2 com consequente aumento da atividade de fosfatase.

Além de ser responsável pela indução de alterações morfológicas e funcionais ligadas à carcinogênese, a infecção por amostras CagA de H. pylori, contendo mais de um segmento C no sítio EPIYA, interfere em várias vias de sinalização celular elevando a expressão de citocinas que também estão ligadas à gênese do câncer gástrico.

Estudos conduzidos por nosso grupo demonstraram que a infecção por amostras vacA s1m1 e CagA-positivas está associada com risco aumentado de câncer gástrico em Minas Gerais e no Ceará. Infecção por amostras CagA-positivas contendo maior número de sítios EPIYA-C está associada com lesões pré-malignas como atrofia e metaplasia gástrica e com risco aumentado de câncer gástrico distal.

No Ceará, onde a prevalência de câncer gástrico é muito elevada, a infecção por amostras de $H$. pylori vacA s1m1 e CagA carreando maior número de EPIYA-C é significativamente mais frequente em familiares de primeiro grau de pacientes com câncer gástrico que em indivíduos que não têm história familiar da doença. À semelhança do que é observado na UP, vacA s1, i1, d1 e m1 estão associados com um risco aumentado de câncer gástrico.

\subsubsection{FATORES AMBIENTAIS}

A ingestão de sal e de alimentos com teor de sal elevado tem sido associada a risco aumentado de câncer gástrico. Por outro lado, há evidências de que a ingestão de vegetais crus e de frutas diminui o risco da doença, o que tem sido atribuído dos antioxidantes, que protegem a mucosa gástrica contra lesões oxidativas.

O hábito de fumar tabaco está associado com um risco aumentado de câncer em geral, inclusive do câncer gástrico, tanto o proximal quanto o distal, em ambos os sexos. Embora os mecanismos associados não sejam completamente conhecidos, é possível que a fumaça que contém inúmeras substâncias carcinogênicas, promova lesão na mucosa gástrica direta ou indiretamente pela corrente sanguínea.

\subsection{HISTÓRIA NATURAL DA INFECC̣ÃO POR H. PYLORI}

A infecção pelo $H$. pylori sempre cursa com gastrite à histologia. O tipo e o grau da gastrite determinam a evolução clínica. Quanto à localização, três tipos principais de gastrite são descritos: pangastrite de intensidade leve, gastrite predominantemente antral e pangastrite atrófica. No primeiro fenótipo, mais frequentemente observado, a gastrite não é acompanhada de complicações e há poucas alterações na secreção gástrica de ácido. O padrão é observado comumente nos individuos assintomáticos e que geralmente não desenvolvem doença gastrointestinal grave. A gastrite que se localiza predominantemente no antro gástrico, 
denominada de fenótipo de úlcera duodenal, acomete até $15 \%$ dos indivíduos infectados. Nesse padrão, a concentração de gastrina e produção gástrica de ácido estão geralmente elevadas e há comprometimento dos mecanismos de inibição da secreção gástrica, com consequente risco aumentado de UD e/ou úlcera pré-pilórica. Finalmente, a gastrite com fenótipo de câncer gástrico caracteriza-se por ser uma pangastrite acompanhada de alterações atróficas, metaplasia intestinal, e hipo ou acloridria, hipergastrinemia e diminuição dos níveis séricos de pepsinogênio I (PGI), bem como da relação PGI/PGII. Esse padrão é visto em aproximadamente $1 \%$ dos indivíduos infectados e decorre da inflamação crônica induzida pela infecção, associando-se ao aparecimento do câncer gástrico (Figura 27.2).

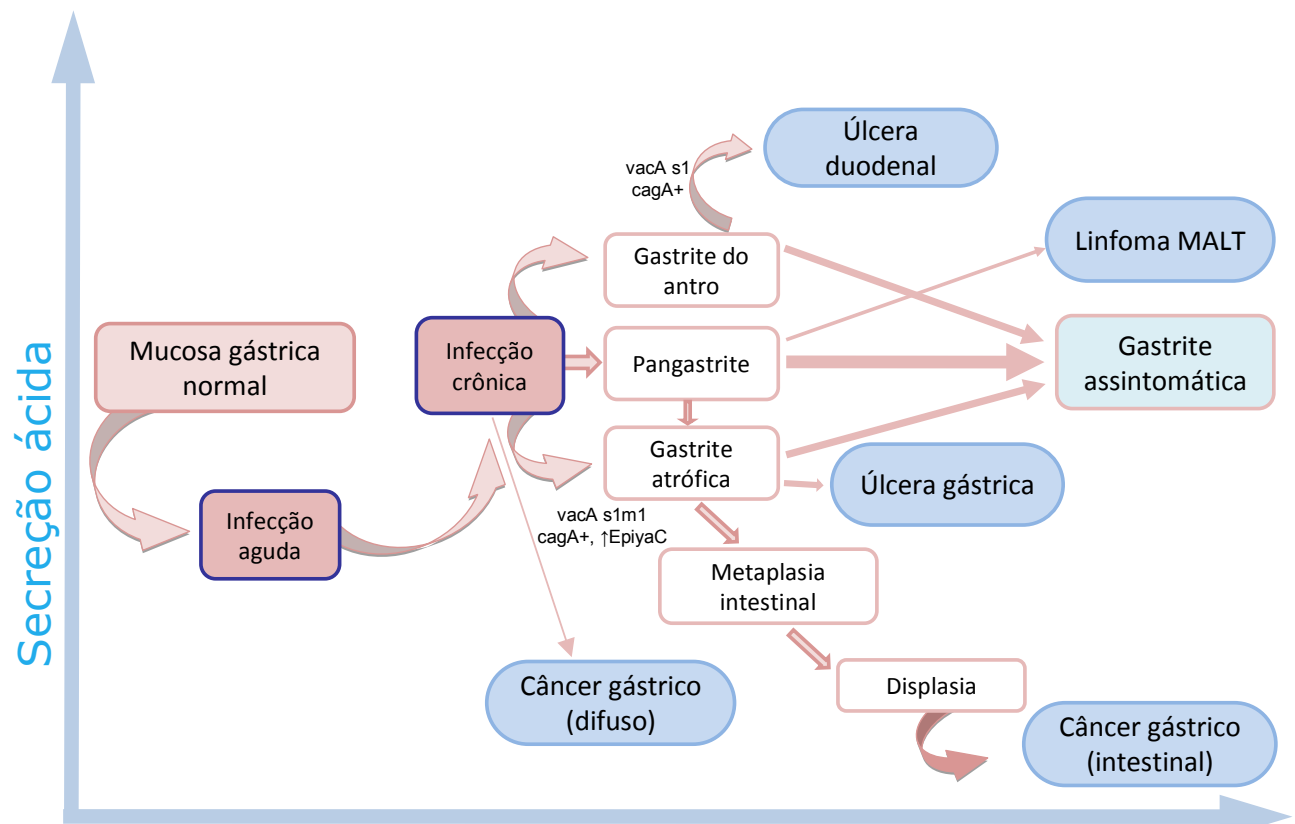

idade

Figura 27.2 - Evolução da infecção por H. pylori. A infecção é adquirida predominantemente na infância, persiste por toda a vida do indivíduo e cursa com inflamação, cujo padrão de distribuiç̣̃o determina o desfecho em doenças ou não. $\mathrm{Na}$ grande maioria dos indivíduos, a gastrite aguda evolui para gastrite ou pangastrite crônica de intensidade leve, sem complicações. A gastrite pode ficar restrita ao antro gástrico sem alterar a secreção ácida predispondo à úlcera duodenal. Em parte dos individuos com pangastrite crônica pode ocorrer o aparecimento de úlcera péptica gástrica ou lesão evolui para gastrite crônica atrófica, metaplasia intestinal, displasia e finalmente 0 carcinoma intestinal. Finalmente, em individuos com gastrite crônica leve, a infecç̃õo pode também evoluir para o linfoma gástrico do tipo MALT. Embora os mecanismos envolvidos na progressão da infecção para as diferentes doenças não sejam completamente conhecidos, fatores de virulência da bactéria, genética do hospedeiro e fatores ambientais são cruciais para o desfecho da infecç̃ão. Figura adaptada de Sauerbaum \& Michetti. N England J Medicine: v374:1175-86, 2010. 


\subsection{CONCLUSÕES}

Atualmente o $H$. pylori é reconhecido como o principal agente etiológico da UP e sua erradicação com antimicrobianos leva à cura da doença, uma vez que a reinfecção ocorre em menos do $1 \%$ da população adulta. Outra causa frequente de UP é o uso crônico de AINEs para o tratamento de doenças inflamatórias crônicas, que são cada vez mais frequentes em decorrência do aumento da expectativa de vida da população mundial.

À semelhança da UP, o carcinoma gástrico também distal decorre da infecção pelo H. pylori; entretanto, essas doenças são excludentes com mecanismos fisiopatológicos distintos. $\mathrm{Na}$ úlcera duodenal, a gastrite não se estende ao corpo gástrico e a secreção gástrica ácida é normal ou aumentada. Diferentemente, nos indivíduos sem úlcera duodenal, o corpo gástrico não é preservado e em alguns deles a gastrite do corpo evolui com hipocloridria/acloridria e atrofia caracterizando os indivíduos predispostos ao carcinoma gástrico.

Além dos marcadores de virulência da bactéria, fatores ligados ao hospedeiro, que, em última instância modula a resposta imunológica/inflamatória à infecção, são essenciais na gênese da doença.

\section{REFERÊNCIAS BIBLIOGRÁFICAS}

MARSHALL, B. J.; WARREN, J. R.: Unidentified curved bacillus on gastric epithelium in active chronic gastritis. Lancet. 1: 1273-1275, 1983.

SUERBAUM, M. D. S.; MICHETTI, P. Helicobacter pylori Infection. Review Article. N. Engl. J. Med. 347(15): 1175-1186, 2002.

WOODLAND, P. J.; STUBBS, B. Peptic ulcer disease. InnovAiT. 2(8): 486-492, 2009.

CHAN, F. K. L.; LEUNG, W. K. Peptic-ulcer disease. The Lancet. 360: 933-941, 2002.

YUAN ,Y.; PADOL, . T.; HUNT, R. H. Peptic ulcer disease today. Nature. 3(2): 80-89, 2006.

SANDLER, S. R. ET AL. The Burden of Selected Digestive Diseases in the United States. Gastroenterology. 122: 1500-1511, 2002.

LAINE, L.; TAKEUCHI, K.; TARNAWSKI, A. Gastric mucosal defense and cytoprotection: bench to beside. Gastroenterology. 135: 41-60, 2008. 
SCHUBERT, M. L.; PEURA, D. A. Control of gastric acid secretion in health and disease. Gastroenterology. 134: 1842-1860, 2008.

YEOMANS, N. D. The ulcer sleuths: The search for the cause of peptic ulcers. Journal of Gastroenterology and Hepatology. 26: 35-41, 2011.

FURUTA, T. R. Interleukin 1-Polymorphisms Increase Risk of Hypochlorhydriaand Atrophic Gastritis and Reduce Risk of Duodenal Ulcer Recurrence in Japan. Gastroenterology.123: 92-105, 2002.

HATAKEYAMA, M. Helicobacter Pylori and gastric carcinogenesis. J of Gastroenterology. 44: 239-48, 2009.

IARC. Monographs on the evaluation of carcinogenic rsiks to humas. Schistosomes, liver flukes and Helicobacter pylori. Lyon (France): International Agency for Research on cancer, 1994.

CORREA, P. Human gastric carcinogenesis: a multistep multifactorial processfirst American Cancer Society Award Lecture on Cancer Epidemiology and Prevention. Cancer Research. 52: 6735-40, 1992.

CORREA, P.; HAENSZEL, W.; CUELLO, C. et al. A model for gastric cancer epidemiology. Lancet. 2: 58-80, 1975.

COVER, T. L.; BLASER, M. J. Helicobacter pylori in health and disease. Gastroenterology. 136: 1863-73.

BLASER, M. J.; PEREZ-PEREZ, G. I.; KLENTHOUS, H. et al. Infection with Helicobacter pylori strains possessing cagA is associated with an increased risk of developing adenocarcinoma of the stomach. Cancer Research. 55: 3111-5, 1995.

ONISHI, N. ET AL. Transgenic expression of Helicobacter pylori CagA induces gastrointestinal and hematopoietic neoplasms in mouse. Proceed Natl Acad Sci. 105: 1003-1008, 2008.

HIGASHI, H. ET AL. SHP-2 tyrosine phosphatase as an intracellular target of Helicobacter pylori CagA protein. Science. 295: 683-6, 2002.

GUILLIFOR, P.; HOPKINS, J.; HARRAWAY. et al. E-cadherin-gemline mutations define in familial gastric cancer. Nature. 392: 402-402, 1998.

SHANKS AM, EL OMAR EM. Helicobacter pylori infection, host genetics and gastric cancer. J. Dig. Dis. 10: 157-64, 2009. 
MCCOL, K. E. L.; GOING, J. J. Aetiology and classfication of adenocarcinoma of the gastroesophageal junction/cardia. Gut. 59: 282-4, 2010.

SAUERBAUM, S.; MICHETTI, P. Helicobacter pylori infection. N. Engl. J. Med. 347: 1175-86, 2002.

BATISTA, S. A.; ROCHA, G. A.; ROCHA, A. M.; SARAIVA, I. E.; CABRAL, M. M.; OLIVEIRA, R. C.; QUEIROZ, D. M. Higher number of Helicobacter pylori CagA EPIYA $\mathrm{C}$ phosphorylation sites increases the risk of gastric cancer, but not duodenal ulcer. BMC Microbiol. 11: 61, 2011.

BUNNEY, T. D.; KATAN, M. Phosphoinositde signaling in cancer: beyond P13K and PTEN. Nat. Rev. Cancer. 10: 342-352. 